\title{
Periurbano y ordenamiento territorial en ciudades intermedias uruguayas. El caso del plan local de Florida y sur microregión
}

\author{
Periurban spaces and land planning in uruguayan \\ intermediate cities. The local plan of land use of Florida \\ city
}

Altmann Macchio, Leonardo

Leonardo Altmann Macchio Sobre el autor laltmann@fadu.edu.uy

Universidad de la República Oriental del Uruguay, Uruguay

PAPELES del Centro de Investigaciones de la Facultad de Ciencias Jurídicas y Sociales de la UNL Universidad Nacional del Litoral, Argentina

ISSN: 1853-2845

ISSN-e: 2591-2852

Periodicidad: Semestral

vol. 12, núm. 23, 2021

papelesdelcentro@fcjs.unl.edu.ar

Recepción: 30 Agosto 2021

Aprobación: 15 Octubre 2021

URL: https://doi.org/10.14409/p.v12i23.10779

\section{cc) (i) (2)}

Esta obra está bajo una Licencia Creative Commons AtribuciónNoComercial-CompartirIgual 4.0 Internacional.
Resumen: El artículo analiza la implementación local de la Ley de Ordenamiento Territorial y Desarrollo Sostenible uruguaya en una ciudad intermedia de enlentecido incremento poblacional pero con significativas transformaciones en uso y actividades de su suelo periférico. En ese sentido, la indagación se detiene en el tratamiento que desde el diagnóstico y propuesta, el instrumento planificador plantea de las áreas de borde rural-urbano. De esta manera, se logra apreciar fenómenos de periurbanización por fuera de los territorios metropolitanos, y el papel de las tendencias de largo plazo en la ocupación del suelo, colocando al marco del ordenamiento territorial a consolidar un modelo territorial que muestra más inercias que innovación.

Palabras clave: ciudades intermedias, ordenamiento territorial, periurbano, expansión urbana, Uruguay.

\begin{abstract}
This paper analyzes the local implementation of the Uruguayan Law of Land Use and Sustainable Development in an intermediate city with a slow population increase but with significant changes in the use and activities of its peripheral land. In this sense, the inquiry stops at the treatment that, from the diagnosis and proposal, the planning instrument raises of the rural-urban border areas. In this way, it is possible to appreciate peri-urbanization phenomena outside the metropolitan territories, and the role of longterm trends in land occupation, placing the framework of land use planning to consolidate a territorial model that shows more inertia than innovation.
\end{abstract}

Keywords: intermediate cities, land use, periurban spaces, urban sprawl, Uruguay.

\section{Introducción}

Florida (35.000 habitantes) es una ciudad intermedia uruguaya, situada 100 $\mathrm{km}$ al norte de Montevideo (la capital del país, donde vive el $40 \%$ de los 3,5 millones de uruguayos). La ciudad se sitúa sobre la ruta nacional $n^{\circ} 5$, un estructurador vial nacional que conecta con la ciudad del Rivera, 500 km, 
en el extremo norte del país y sobre la frontera con el Brasil (Imagen 1). Florida ha tenido en las últimas décadas un discreto incremento de población aunque significativas transformaciones urbanas y de actividades y usos del suelo, particularmente en su interfase urbano-rural, con una heterogeneidad e intensidad que ha denota un emergente proceso de periurbanización. En el caso uruguayo, si bien la conformación periurbana ha sido notoria en el área metropolitana de Montevideo desde finales del siglo XX (Artigas et al, 2002; Goldaracena, 2008, Lecuna y Schelotto, 2015; Medina, 2017), la valoración de las transformaciones de los bordes en las ciudades intermedias uruguayas es un ámbito poco explorado y que ha enfatizado procesos en la expansión física desde lo urbano- habitacional (Martínez y Altmann, 2020) o acentos conceptuales desde los marcos planificadores (Ligrone, 2016).

En el territorio uruguayo, la sanción de la Ley de Ordenamiento Territorial y Desarrollo Sostenible (LOTDS, Ley 18.308, de 2008) generó a nivel nacional un sistema planificador con casi un centenar de normaivas derivadas que incluyen instrumentos de ordenamiento territorial en diferentes escalas geográficas (local, departamental, regional, nacional). Para la LOTDS, el ordenamiento territorial es "el conjunto de acciones transversales del estado que tiene por fin mantener y mejorar la calidad de vida de la población, la integración social en el territorio y el uso y aprovechamiento ambientalmente sustentable y democrático de los recursos naturales y culturales" (LOTDS, art. 3). Igualmente, es concebido como función pública, y refiere a un sistema normativo vinculado a las actuaciones de las instituciones del Estado "con competencia a fin de organizar el uso del territorio" (Idem).

La categorización del suelo, es decir la asignación de usos y la previsión de transformación futura, a través de la designación del carácter de urbano, suburbano, rural y el atributo de potencialmente transformable, es una herramienta central del proceso planificador, cuya competencia refiere al nivel departamental (subnacional) de gobierno y debe realizarse en el marco de instrumentos de ordenamiento territorial.

El periurbano no es una categoría de suelo para el marco normativo nacional uruguayo de ordenamiento territorial. Aunque el proceso de transformación de bordes urbanos puede advertirse en la presencia contigua y desestructurada de suelos urbanos no consolidados a nivel infraestructural, enclaves suburbanos (industriales, residenciales, logísticos) y ámbitos rurales productivos".

Las lecturas diagnósticas y la propuesta de planificación territorial realizadas en su Plan Local de Ordenamiento Territorial y Desarrollo Sostenible (2016) evidencian una validación de los procesos previos y la dificultad de articular un modelo renovado de usos del suelo. 


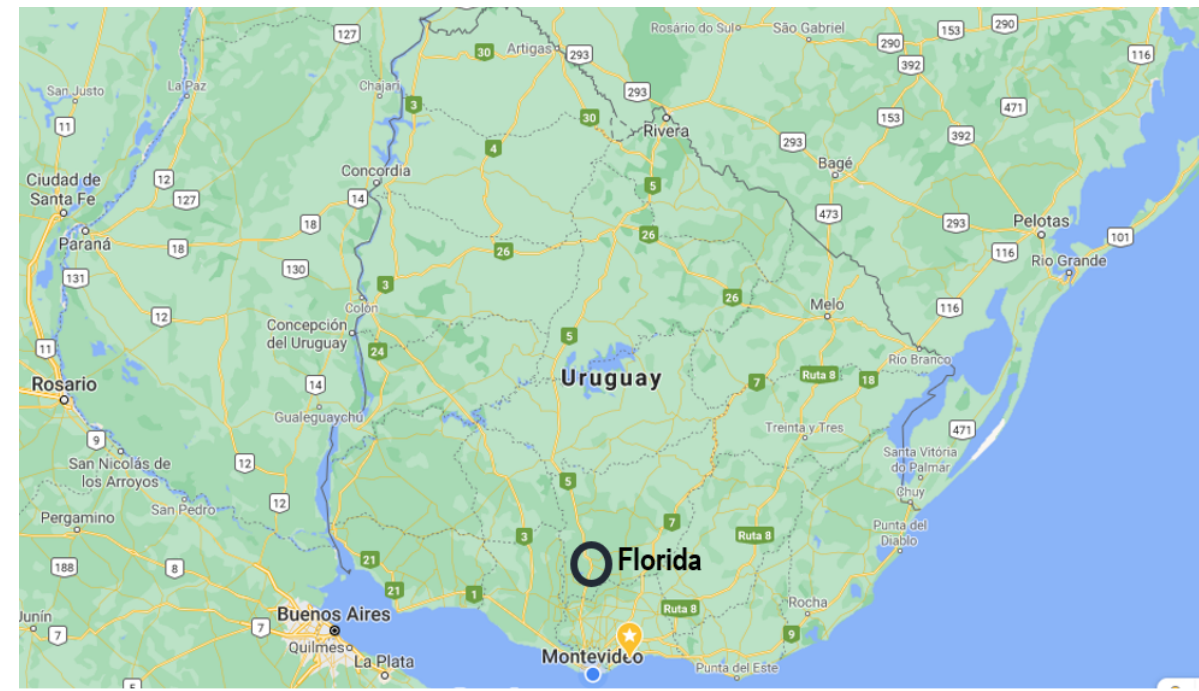

Imagen 1.

Ubicación de Florida dentro del territorio uruguayo.

Elaboración propia sobre captura de Google Maps.

De manera exploratoria, se plantea una mirada para comprender la política de ordenamiento territorial inspirada en la noción de acción pública (Amin 2005, Le Gales y Lascoumes, 2014, Thoenig, 1997). Es decir, jerarquizando no solo su formulación y definición de objetivos de una política pública sino los acentos del flujo de implementación, interpretación y apropiación local, en este caso de una normativa nacional, evidenciando acentos escalares que dan lugar a una geografía diferenciada por su contexto y trayectoria.

La respuesta desde el marco planificador a las tensiones derivadas de la agenda territorial local, en particular las derivaciones de la renovación de la agroindustria (su producción reescalada para el comercio regional y global; sus instalaciones, servicios y logística asociada) y nuevos productos residenciales (urbanizaciones campestres, barrios cerrados o semi cerrados), nos permite analizar el ordenamiento territorial en sus posibilidades de acción sobre el territorio heredado y el papel significativo de lo que denominamos microgeografías regulatorias.

\section{Marco de discusión: la regulación local de los procesos de urbanización global}

\subsection{Escalas y facetas conceptuales de la urbanización contemporánea y su abordaje empirico}

La discusión actual sobre lo urbano manifiesta una supuesta "crisis epistemológica" dentro de la cual para indagar los procesos de urbanización se pone en cuestión la cualidad de lo urbano como asentamiento fijo, limitado y universalmente generalizable (Brenner y Schmid, 2015). Esta sugerente línea argumental observa a las transformaciones urbanas como un proceso permanente de destrucción creativa del espacio social heredado, donde contexto y trayectorias territoriales asumen un rol determinante, dando lugar a variadas geografías. 
Esta polémica contemporánea que enfatiza la discusión teórica sobre la ciudad, lo urbano y la urbanización, en términos relacionales y de procesos sociales multiescalares, tiene una contracara en la histórica polémica sobre las definiciones de lo urbano en términos administrativos, gestión territorial y de los sistemas estadísticos, donde se determinan efectivamente las condiciones de ocupación del territorio, la asignación de usos y funciones. Allí pueden encontrarse, en el siglo $\mathrm{XX}$, antecedentes que remiten a la Escuela de Chicago y su modelo concéntrico de estructura urbana (Park, Burgess, y Mc Kenzie, 1925) donde se denota una pérdida de densidad de población y vivienda a medida que nos alejamos del centro de negocios, pasando por áreas industriales y residenciales y finalmente suburbanas. Este modelo, que muestra ese degradé en los asentamientos humanos hacia el ámbito rural, si bien tuvo variantes y complejizaciones como modelo sectorial de Hoyt, el modelo polinuclear de Harris y Hullman, o interpretaciones desde la trayectoria latinoamericana, refiere, en definitiva, a una tendencia a la suburbanización como transición entre lo urbano y lo rural.

También es importante recuperar la trayectoria de los sistemas estadísticos en su búsqueda por homogeneizar definiciones sobre lo urbano. Allí, aparecen recurrentemente: el status legal de los centros poblados, la ocupación urbanohabitacional en términos de aglomeración (umbrales de cantidad de población o densidades) y el papel de subdivisiones administrativas y si estas incluyen indistintamente territorios urbanos y rurales o no. ${ }^{1}$

La multiplicidad de criterios para determinar lo "urbano" a nivel nacional es uno de los aspectos que Brenner y Schmid (2015) ponen en cuestión al relativizar los discursos totalizadores de la "era urbana". Sin embargo, esa propia dispersión, suele estar condicionada por la propia trayectoria de los territorios (tan valorada por estos mismos autores en tanto geografías diferenciadas del capitalismo) y que hace a las cuestiones multiescalares de usos del suelo y actividades, la definición de entidades administrativas y el marco regulatorio del uso del suelo.

En efecto, la dicotomía urbano-rural es puesta en cuestión tanto por los estudios teóricos que plantean el agotamiento de categorías conceptuales para dar cuenta de los actuales procesos de transformación socio-espacial en múltiples escalas, como en la gestión urbana y los análisis empíricos. Desde las conformaciones urbanas discontinuas espacialmente pero articuladas funcionalmente (por ejemplo las citadas por Ascher, 1995, en términos de "metápolis") a la idea de la ciudad "difusa" (Indovina, 2005), el límite de lo urbano se presenta crecientemente complejizado, en particular al observar los ámbitos locales.

\subsection{Las áreas de borde: procesos y variantes2}

La complejización de los espacios de borde de las ciudades occidentales, en términos de usos del suelo y actividades, ha dado lugar a una agenda propia, donde destacan problemáticas ambientales, sociales y regulatorias (Barsky, 2005; Allen, 2003; Avila Sanchez, 2001; Hernandez Puig, 2012). Los estudios sobre los bordes urbano-rural cobraron protagonismo desde la década de 1940 cuando los procesos de suburbanización y metropolización en las ciudades norteamericanas, en un contexto de urbanización acelerada, impusieron una reflexión sobre estos novedosos episodios urbanos de la ciudad industrial de la posguerra. En el caso 
europeo, como menciona Brenner (2004) los procesos de suburbanización y conformación de ciudades satélite de las áreas metropolitanas, formaron parte de las estrategias espaciales estatales de los estados de bienestar noratlánticos de mediados del siglo XX.

Avila Sanchez (2001) refiere a que el periurbano retoma el concepto utilizado en la literatura francesa sobre la expansión urbana que incorpora ámbitos productivos rurales, y en el cual se desarrolla agricultura de proximidad ligada a mercados urbanos, integrándose actividades, no necesariamente de carácter primario.

H. Carter (1974) menciona que "el espacio hacia el cual se extiende la ciudad como resultado del proceso de dispersión ha creado el concepto de la franja ruralurbana, un área con características particulares, la cual ha sido solo parcialmente asimilada en el creciente complejo urbano y que sigue siendo en parte rural, ya que muchos de sus residentes viven en el campo, pero no dependen de él, ni social ni económicamente" (Carter, 1974, p. 323) y al identificar estudios acerca de los crecimientos en la ciudad norteamericana a fines de los años 60 , encuentra que "en los límites de la ciudad, en el contexto de la franja, es característico una gran mezcla de usos del suelo" (idem, p. 324).

Hernandez Puig (2012) refiere a que R. Colledge (1960) caracterizaba estas franjas de borde para las áreas metropolitanas, estudiando el caso australiano, considerando que en el espacio periurbano existe una pauta de ocupación del territorio en continuo cambio, con explotaciones agrícolas intensivas y de pequeño tamaño, población móvil y en baja densidad, dotación incompleta de servicios y equipamientos público y operaciones urbanas especulativas.

En los procesos de crecimiento de las ciudades anglosajonas durante el siglo $\mathrm{XX}$, las periferias comenzaron a tener una connotación como lugar de segunda residencia y luego de residencia de las clases altas. La valoración de los ámbitos por fuera de la contaminación y congestión de la ciudad, motivaron los modelos de la ciudad-jardín. Era una periferia planificada donde el modelo territorial implicaba una baja ocupación y la valoración de atributos ambientales y paisajísticos.

En Latinoamérica, las periferias tuvieron otro recorrido y significación, ya que "ni el desarrollo capitalista en América Latina ni la urbanización que generó han seguido el mismo camino histórico ni iguales modelos, ni ocurrieron en los mismos tiempos y ritmos seguidos por estos procesos en Europa o Estados Unidos en los siglos XIX y XX” (Pradilla Cobos, 2014, p. 38).

Barsky (2005) coloca al periurbano dentro de nuevas configuraciones territoriales derivadas del neoliberalismo, donde la falta de procesos planificadores en las periferias arroja dinámicas caracterizadas por problemas sociales y ambientales y un mercado de suelo poco transparente, donde subyace la expectativa de integración de estas tierras a la ciudad, independientemente de en qué plazos ello eventualmente suceda.

Estos antecedentes refieren a la periurbanización como proceso que evidencia un conflicto entre usos rurales y urbanos-habitacionales, con velocidad de transformación física y recambio de actores. En los análisis mencionados, la dimensión de la gestión urbano-territorial no tiene un lugar destacado en la agenda, sino a través de lateralizaciones que destacan la liberalización de los marcos regulatorios de uso del suelo o procesos por fuera del mismo, como determinantes de la conformación de los periurbanos. Valorando el papel de 
la planificación y gestión urbano-territorial en la conformación espacial tanto en la asignación de usos como en sus implicancias para en el direccionamiento de inversiones, se ve relevante este acercamiento al periurbano desde lo que denominamos "microgeografías regulatorias", que hacen al marco local de usos del suelo y actividades, la cual también denota permeabilidades de otras escalas.

\section{El caso y su contexto}

3.1 El periurbano en Uruguay: tamaño predial, usos del suelo y dotación de infraestructura como factores para categorizar el suelo

Como fue mencionado, los territorios periurbanos no han tenido un lugar destacado en la cuestión urbana uruguaya, al tiempo que los análisis de la implementación local de la LOTDS son emergentes. La especificidad regulatoria de espacios de "transición" entre lo rural y urbano en el país, tiene una trayectoria con cuatro etapas estructuradas por normativas de gestión urbanoterritorial del nivel nacional, observándose una creciente complejización en la conceptualización y abordaje de los bordes (Tabla 1). El momento inicial está asociado a la aplicación de la normativa indiana sobre centros urbanos. Las ciudades uruguayas fundadas por la corona española utilizaron el denominado "modelo ciudad- territorio" (Alvarez Lenzi, 1972). Allí, se definía un centro urbano determinado por un amanzanado en cuadrícula regular. Luego de éste se ubicaba el "ejido", posteriormente una zona de chacras y finalmente estancias. El modelo indiano implicaba un complejo dispositivo espacial multiescalar en términos de estrategias de ocupación del suelo y subdivisión predial, y estaba orientado a la producción agropecuaria, ya que la potestad de fundar ciudades sobre costas oceánicas (puertos, de perfil comercial) era privativa de la corona. 
Tabla 1.

Marcos normativos y procesos territoriales vinculados al borde urbano-rural en el caso uruguayo.

\begin{tabular}{|c|c|c|c|c|}
\hline $\begin{array}{l}\text { Normativas } \\
\text { nacionales de uso } \\
\text { del suelo y } \\
\text { desarrollo urbano }\end{array}$ & $\begin{array}{l}\text { Leyes de } \\
\text { Indias ( } \mathrm{S} \text {. } \\
\text { XVIII y XIX) }\end{array}$ & $\begin{array}{l}\text { Leyes de } \\
\text { Indias. } \\
\text { Formato Era } \\
\text { Republicana } \\
(1830-1946)\end{array}$ & $\begin{array}{l}\text { Ley de } \\
\text { Centros } \\
\text { Poblados } \\
(1946)\end{array}$ & \begin{tabular}{|l} 
Ley de \\
Ordenamiento \\
Territorial y \\
desarrollo \\
sostenible \\
(2008) \\
\end{tabular} \\
\hline $\begin{array}{l}\text { Modelo } \\
\text { territorial: }\end{array}$ & $\begin{array}{l}\text { Ciudad- } \\
\text { territorio. }\end{array}$ & $\begin{array}{l}\text { Centro } \\
\text { urbano y } \\
\text { entorno rural } \\
\text { productivo }\end{array}$ & $\begin{array}{l}\text { Unidad } \\
\text { vecinal y } \\
\text { área } \\
\text { productiva } \\
\text { circundante } \\
\end{array}$ & $\begin{array}{l}\text { Territorio } \\
\text { integrado como } \\
\text { continuo } \\
\text { urbano-rural. }\end{array}$ \\
\hline $\begin{array}{l}\text { Tratamiento de } \\
\text { los bordes }\end{array}$ & $\begin{array}{l}\text { Graduación } \\
\text { urbano- rural } \\
\text { basada en } \\
\text { definición de } \\
\text { áreas de } \\
\text { pastoreo o } \\
\text { cultivo } \\
\text { utilizados } \\
\text { colectivamente } \\
\text { por la } \\
\text { población. }\end{array}$ & $\begin{array}{l}\text { Graduación } \\
\text { urbano- rural } \\
\text { basada en } \\
\text { Subdivisión } \\
\text { predial. }\end{array}$ & $\begin{array}{l}\text { Graduación } \\
\text { urbano- } \\
\text { rural } \\
\text { basada en } \\
\text { subdivisión } \\
\text { predial (1 a } \\
5 \text { hectáreas) }\end{array}$ & $\begin{array}{l}\text { Heterogénea } \\
\text { transición } \\
\text { urbano- rural } \\
\text { con diversas } \\
\text { figuras } \\
\text { normativas: } \\
\text { Suelo urbano no } \\
\text { consolidado, } \\
\text { suelo } \\
\text { suburbano, } \\
\text { atributo de } \\
\text { potencialmente } \\
\text { transformable. }\end{array}$ \\
\hline $\begin{array}{l}\text { Actividades en } \\
\text { bordes }\end{array}$ & $\begin{array}{l}\text { Producción } \\
\text { agropecuaria } \\
\text { de } \\
\text { proximidad. }\end{array}$ & $\begin{array}{l}\text { Producción } \\
\text { agropecuaria } \\
\text { de } \\
\text { proximidad } \\
\text { en pequeños } \\
\text { predios de } \\
\text { propiedad } \\
\text { privada y } \\
\text { pequeñas } \\
\text { industrias. }\end{array}$ & $\begin{array}{l}\text { Producción } \\
\text { agropecuaria } \\
\text { de } \\
\text { proximidad } \\
\text { en pequeños } \\
\text { predios de } \\
\text { propiedad } \\
\text { privada y } \\
\text { enclaves } \\
\text { industriales. }\end{array}$ & $\begin{array}{l}\text { Producción } \\
\text { agropecuaria, } \\
\text { emprendimientos } \\
\text { residenciales, } \\
\text { enclaves } \\
\text { industriales o } \\
\text { logísticos. }\end{array}$ \\
\hline $\begin{array}{l}\text { Conceptualización } \\
\text { del borde } \\
\text { asociada a la } \\
\text { geografía } \\
\text { regulatoria }\end{array}$ & $\begin{array}{l}\text { Ejido colonial, } \\
\text { propios. }\end{array}$ & $\begin{array}{l}\text { Ejido } \\
\text { republicano. }\end{array}$ & $\begin{array}{l}\text { Centro } \\
\text { poblado de } \\
\text { huertos y } \\
\text { zonas } \\
\text { Suburbanas. }\end{array}$ & \begin{tabular}{|l} 
Suelo \\
suburbano, \\
urbano no \\
consolidado.
\end{tabular} \\
\hline
\end{tabular}

Elaboración propia a partir de Klaczco y Rial (1981), Musso (2004), Martínez y Altmann (2016).

Es importante destacar que la vida colonial de las ciudades uruguayas fue breve, ya que el proceso urbanizador en la "Banda Oriental” comenzó recién a mediados del siglo XVIII, fundándose apenas una decena de poblados antes del inicio del período revolucionario (1811).

De la aplicación (que no fue rigurosa) de la normativa indiana antes de 1830 en el actual territorio uruguayo se desprende que:

- Todos los centros urbanos fundados delimitaron su ejido aunque con diferentes criterios sobre su formalización (a veces geométrico y en otras considerando la geografía del lugar). El ejido era una zona libre, sin edificios ni cultivos, común a todos los vecinos, espacio de recreo, salida del ganado de los pobladores del núcleo urbano y reserva para futuras extensiones del amanzanado si la población creciera. También cumplía funciones defensivas. 
- La zona de dehesas y propios fue manejada bajo la denominación común de propios, coexistiendo el laboreo comunal y los predios propiedad de los cabildos.

- Las "suertes de estancia" fueron repartidas a todos los pobladores indistintamente de la composición familiar.

En la etapa independiente, el Estado Uruguayo propició la fundación de nuevas ciudades con fin de administración territorial y consolidación de la frontera seca con el Brasil. Formalmente se mantuvo el damero regular y la delimitación de una zona contigua dividida en predios de tamaño intermedio denominada genéricamente "ejido" aunque el modelo de ciudad-territorio fue dejado de lado (Klaczko y Rial, 1981). Pero en la ciudad republicana el suelo empezó a tomar valor de cambio. El poblador de los tiempos coloniales recibía su parcela para cultivo, edificar su casa y radicarse, lo cual implicaba una preponderancia del valor de uso del suelo. En la era republicana, como señalan Klaczko y Rial (1981, p. 44), "el poblador fue solo un comprador de tierra, que, si pudo se convirtió a su vez en vendedor e incluso si siguió un camino ascendente fue especulador él también”. En ese marco, en 1876, el presidente de facto, Cnel. Lorenzo Latorre, decretó que las tierras fiscales pasarían a ser enajenadas únicamente "por valor corriente fijado por tasación, (por lo que) las tierras públicas dejaron de ser para el Estado, un medio de promocionar una política poblacional para convertirse en fuente de recursos presupuestales" (Klaczko y Rial, 1981, p. 44).

En efecto, ese "ejido" definido como la zona de mayor proximidad a la "planta urbana" de las ciudades, adquirió dinamismo desde finales del XIX, en tanto continuó recibiendo actividades productivas y fue "banco de tierras" del crecimiento de las ciudades.

En la normativa de centros poblados de 1946, el tamaño predial (se definieron predios menores a 5 hectáreas como umbral máximo de predios urbanos, salvo los departamentos de Montevideo y Canelones - los más poblados del país- donde ese límite se bajó a 3 hectáreas) y la estructura circulatoria aparecieron como elementos centrales para discriminar los ámbitos urbanos de los rurales:

"Si dichos predios son menores de una hectárea cada uno, el centro poblado se entenderá pueblo, villa o zona urbana o suburbana. Si los predios independientes creados son mayores de una hectárea de superficie cada uno y menores de los límites fijados en el inciso primero, el centro poblado a cuya formación se tiende, se entenderá como centro poblado de "Huertos" (Ley 10.723, de Centros Poblados, 1946).

La normativa derivada de la ley de centros poblados implicó que cada departamento dentro su autonomía y competencias establecidas en ésta norma, y en la ley orgánica municipal, generara diferentes estrategias de zonificación. En el caso de los viejos ejidos de las ciudades, la mayor parte fueron asignados como suburbanos, o en parte como zona de huertos, atendiendo a la conformación de predios de entre 1 a 5 hectáreas.

Los propios gobiernos departamentales, ávidos de recursos genuinos (en promedio la mitad del presupuesto de la intendencias departamentales se solventa con transferencias directas del gobierno nacional), propiciaron categorizar suelos con carácter urbano o suburbano para aumentar su capacidad 
de captar tributos por contribución inmobiliaria, no solo porque el suelo urbano o suburbano por su mayor intensidad de uso tributa más que el rural, sino porque la contribución inmobiliaria rural en Uruguay es recaudada centralmente por el gobierno nacional.

El siguiente cambio en la legislación nacional se dio con la Ley de Ordenamiento Territorial y Desarrollo Sostenible (LOTDS) en 2008. Ésta norma, estructura un sistema planificador, en el cual interactúan tanto sus decretos reglamentarios (Decretos: 221/09, 400/09 y 523/09), sus modificaciones al articulado original; así como los diferentes tipos de Instrumentos de Ordenamiento Territorial (IOT) definidos en ella, según sus ámbitos espaciales (nacional, departamental, regional, local) o sectoriales de actuación dentro de las ciudades (LOTDS, Arts. 9 a 22).

La LOTDS inauguró una nueva conceptualización sobre lo urbano y su desarrollo en el Uruguay, al definir las categorías de suelo respecto a sus atributos infraestructurales y usos predominantes, así como estableciendo los mecanismos de transformación de categorías, a través del atributo de potencialmente transformable y los programas de actuación integrada, a efectos de evitar la discrecionalidad en el pasaje a suelo urbano:

"Únicamente será posible incorporar terrenos a los suelos categoría urbana y categoría suburbana mediante la elaboración y aprobación de un programa de actuación integrada para un perímetro de actuación específicamente delimitado dentro de suelo con el atributo de potencialmente transformable" (LOTDS, Art. 34).

"El suelo categoría urbana comprenderá las áreas de territorio de los centros poblados, fraccionadas, con las infraestructuras y servicios en forma regular y total, así como aquellas áreas fraccionadas parcialmente urbanizadas en las que los instrumentos de ordenamiento territorial pretenden mantener o consolidar el proceso de urbanización" (LOTDS, Art. 32).

A su vez, se creaba la categoría "suelo suburbano". Esto no remitía a la transición urbano- rural que emergía de la zonificación definida en la ley de centros poblados, sino que refería enclaves o frentes de urbanización con variados usos.

"Suelo Categoría Suburbana: Comprenderá las áreas de suelo constituidas por enclaves con usos, actividades e instalaciones de tipo urbano o zonas en que éstas predominen, dispersos en el territorio o contiguos a los centros poblados, según lo establezcan los instrumentos de ordenamiento territorial.

Son instalaciones y construcciones propias de suelo categoría suburbana las: habitacionales, turísticas, residenciales, deportivas, recreativas, industriales, de servicio, logística o similares". (LOTDS, Art, 33).

La LOTDS especifica que la categorización de suelos se dé dentro de IOT definidos por los departamentos, con garantías ambientales y de participación (Evaluación Ambiental Estratégica, instancias de participación ciudadana: puesta de manifiesto, audiencia pública), coherencia tanto del marco planificador (informes de correspondencia) como con las políticas sectoriales y actuaciones estatales en territorio (informes de incidencia). 


\section{Análisis primario del Plan de Ordenamiento Territorial de Florida y su microrregión (Uruguay) desde su diagnóstico y propuesta}

\subsection{Sintesis del proceso urbanizador en Florida}

Florida, la última ciudad fundada por los españoles en la Banda Oriental (1809), resignificó su papel dentro del sistema urbano uruguayo al pasar a ser capital del creado departamento del mismo nombre (1856). El territorio departamental cuenta con variada actividad agropecuaria donde destaca el protagonismo de la lechería (Imagen 2).

En 1874 el ferrocarril llegó a la ciudad, sobre la vía fundacional del trazado ferroviario uruguayo. Según los criterios de mayor rentabilidad utilizado por las empresas inglesas constructoras del ferrocarril, las estaciones en las ciudades existentes se ubicaron en áreas de borde. De esta forma, y por su emplazamiento en una elevación en un recodo del río Santa Lucía, la ciudad embretó su crecimiento entre la vía del tren y el río. Florida pasó de 21.000 habitantes en 1963 a casi 34.000 en 2011. En el lapso 1985-2011 tuvo una tasa de crecimiento promedio anual de población de $0,64 \%$, menor a la del país urbano $(0,71 \%)$.

Tabla 2.

Evolución demográfica de Florida (1985-2011).

\begin{tabular}{|l|l|l|l|l|l|l|l|}
\hline \multicolumn{2}{|c|}{} & 1985 & 1996 & 2004 & 2011 & $\begin{array}{l}\text { crecimiento } \\
1985- \\
2011\end{array}$ & $\begin{array}{l}\text { Tasa } \\
11-85\end{array}$ \\
\hline \multirow{3}{*}{ Florida } & población & 28.451 & 31.589 & 32.128 & 33.640 & $18 \%$ & $0,64 \%$ \\
\cline { 2 - 8 } & vivienda & 8.263 & 9.843 & 11.425 & 12.745 & $54 \%$ & $1,64 \%$ \\
\cline { 2 - 8 } & hogares & 7.950 & 9.288 & 9.918 & 11.647 & $47 \%$ & $1,45 \%$ \\
\hline
\end{tabular}

Elaboración propia a partir de datos INE

En una mirada longitudinal, el territorio a estudio evidencia patrones heredados del modelo urbano-territorial colonial (S. XIX) con la zona de chacras y ejido de la ciudad, que denota una vocación productiva rural y mayor subdivisión del suelo en las proximidades de la planta urbana y cuya delimitación implicó una carcaza geográfica que hasta la actualidad refiere al área contigua de la ciudad ("microregión").

La Imagen 3 muestra el trazado regular de la zona de chacras de la ciudad a mediados del siglo XIX y los límites de éste, los cuales fueron tomados como microregión para el Plan Local de 2016: los arroyos Pintado y de los Molles, y el río Santa Lucía Chico. También se aprecia la ubicación de la planta urbana de la ciudad hacia el sureste y una mayor subdivisión de los predios de la zona de chacras en los cuadrantes inmediatamente contiguos a la cuadrícula fundacional. 


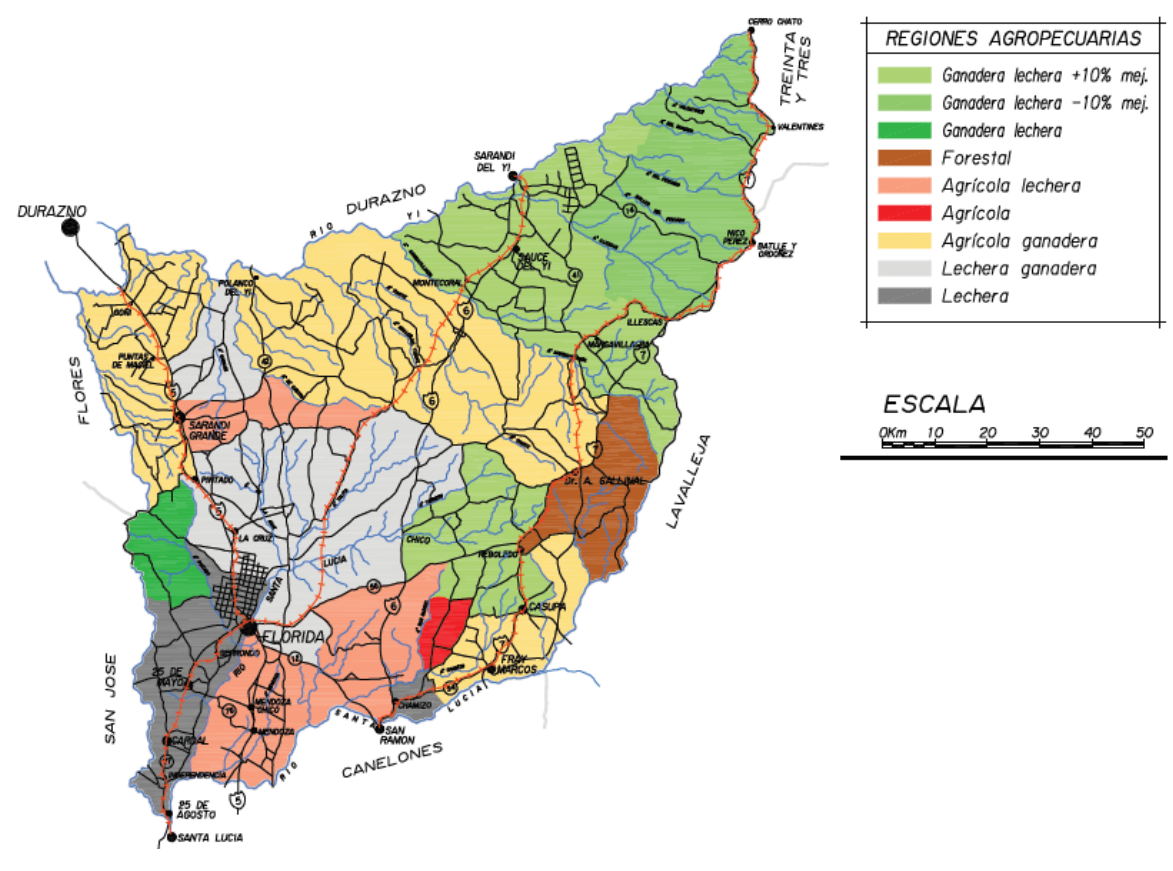

Imagen 2.

Regiones de especialización productiva según Ministerio de Ganadería, Agricultura y Pesca para el departamento de Florida (censo agropecuario 2010). Extraído de la memoria de información del plan local de ordenamiento territorial de Florida. Intendencia de Florida.

Luego, dentro de la urbanización asociada a la era republicana, la ciudad recibe la modernización con la llegada del ferrocarril y su posicionamiento dentro del modelo agroexportador y dependiente, que combinado con un precoz estado de bienestar (1904-1929) signó la trayectoria uruguaya dentro de la urbanización latinoamericana. 


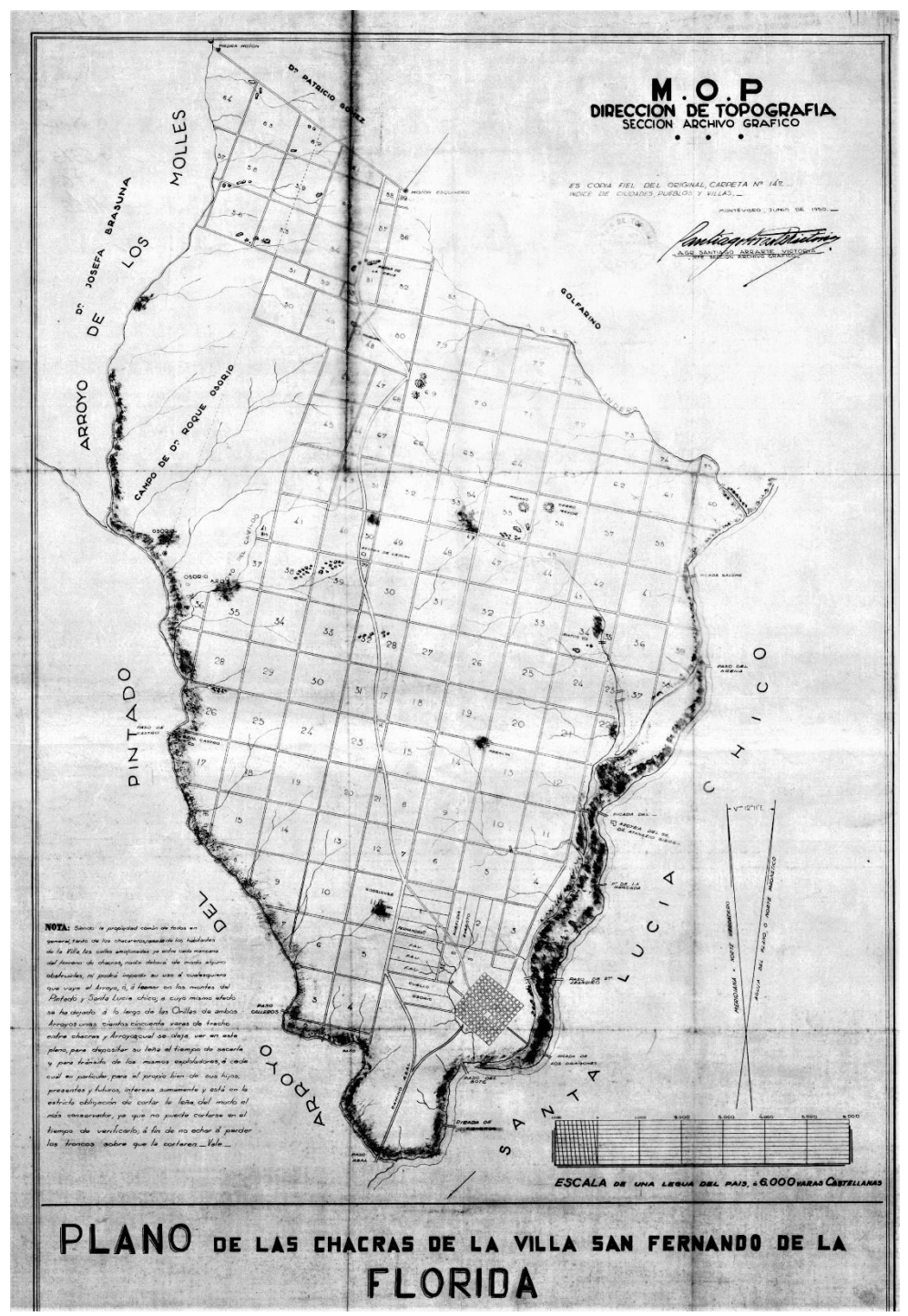

\section{Imagen 3.}

Ejido y chacras de la Villa de Florida (1855).

Extraído de la mapoteca digital de la Biblioteca Nacional de Uruguay.

En las últimas décadas, el área muestra las transformaciones socio-territoriales derivadas de la apertura y desregulación económica iniciada en la década de 1970. En particular, Florida ha sido epicentro de parte de la reconversión de la agroindustria uruguaya en el último medio siglo, cuando luego de acuerdos comerciales con Argentina y Brasil, el sector primario uruguayo comenzó un proceso de reescalamiento que implicó enfocar su producción hacia la exportación, tendencia profundizada luego de la creación del Mercado Común del Sur (MERCOSUR) en 1991 (Oddone, 2010). A pocos kilómetros de la ciudad está situada (desde 1935) una de las principales plantas industriales de la empresa láctea Cooperativa Nacional de Productores de Leche (CONAPROLE) líder del mercado nacional y una de las principales exportadoras del país. 


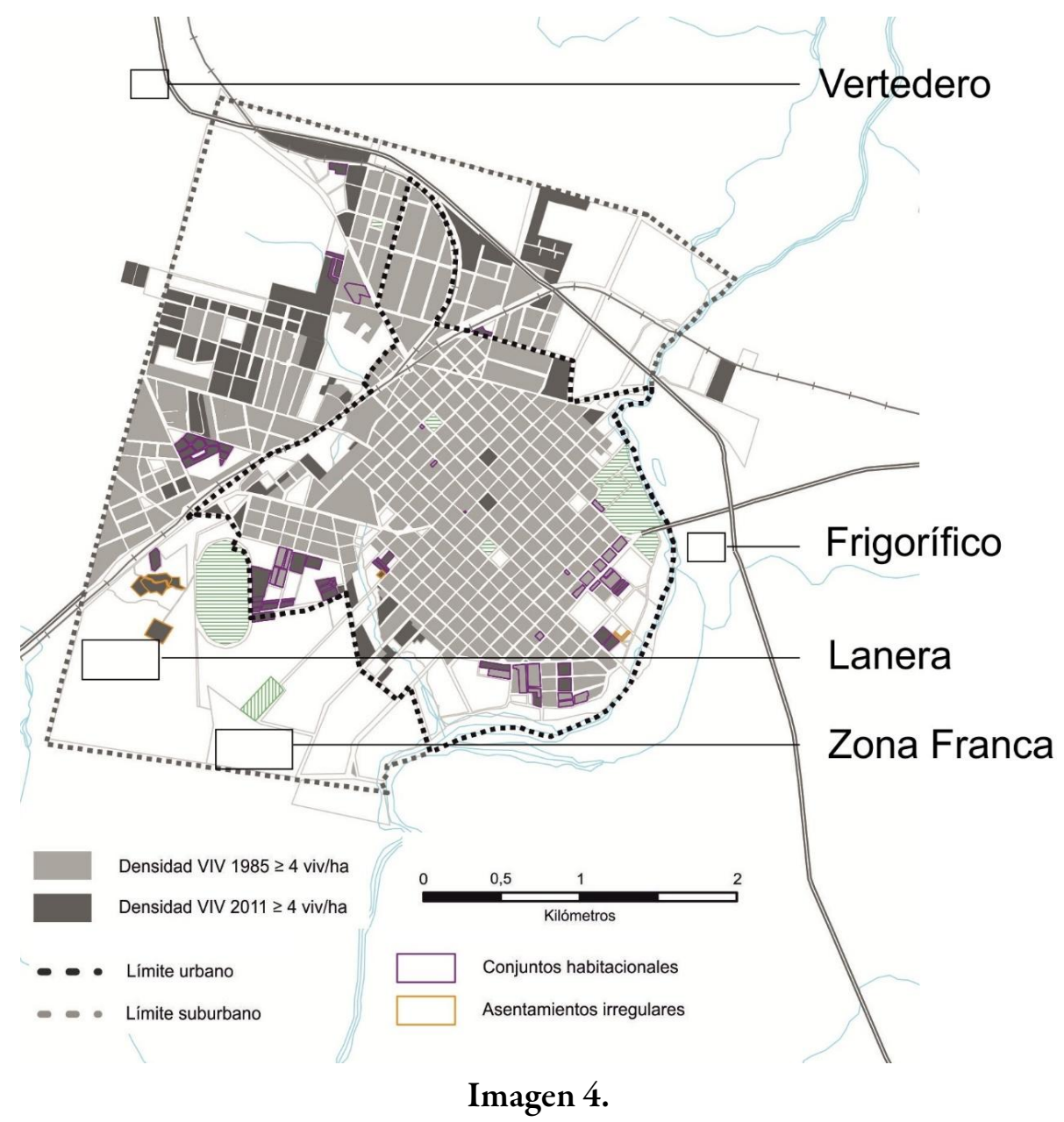

Expansión urbana 1985-2011 y principales estructuradores no habitacionales de la periferia. Elaboración propia a partir de Martínez y Altmann (2020).

Respecto al proceso de urbanización, entre 1985 y 2011 la ciudad sumó casi 100 hectáreas urbanizadas (amplió 25\% en superficie), su población aumentó un $18 \%$ y la vivienda y los hogares aumentaron casi un 50\% (Tabla 2, Imagen 4). De esta forma, se aprecia una expansión bastante equilibrada, ya que en parte importante, las ciudades medias uruguayas en el mismo ciclo mostraron una tendencia a incremento de superficie urbanizada más vinculada al crecimiento de viviendas y hogares que al de población, evidenciando territorialmente el cambio demográfico referente a que los hogares uruguayos aparecen integrados por cada vez menos personas (Cabella, Fernández Soto y Prieto, 2015). A pesar de ello, en esta expansión primó la provisión parcial y ex-post de los servicios básicos de infraestructura urbana (saneamiento en red, pavimentos, escurrimiento de aguas superficiales, alumbrado público) (Martínez y Altmann, 2020).

A esta expansión formal se sumaron seis asentamientos precarios surgidos entre 1996 y 2004 (el mayor de ellos fue realojado en 2014) y enclaves industriales o logísticos. En 1989 en la zona suroeste se estableció una empresa de lavado y peinado de lana; en 1993, al sur de la ciudad se instaló, en un predio de 20 hectáreas, la primera zona franca del interior del país. ${ }^{3}$ El frigorífico, situado a las afueras de la ciudad, la planta industrial de CONAPROLE y el vertedero (basurero) local, son de etapas anteriores a 1985. 
También aparecieron nuevos barrios en baja densidad en entornos rurales, hacia el este (ruta 56), cerca de los cuales se instaló recientemente un parque de energía eólica. También destaca un amplio predio del ejército nacional destinado al asentamiento de unidades y fabricaciones militares.

\section{2: El Plan local de ordenamiento territorial y desarrollo sostenible}

Los instrumentos de ordenamiento territorial (IOT) de escala departamental son decretos departamentales con fuerza de ley en sus ámbitos. ${ }^{4}$ Algunas disposiciones de los IOT son realizables en el marco de las competencias departamentales y otras implican un nivel de coordinación con otros organismos públicos o privados. En todo caso, la categorización del suelo es específica de los departamentos y constituye el elemento central de la política de ordenamiento territorial estructurada por la LOTDS.

Las etapas de elaboración de los IOT están reguladas por la LOTDS y sus decretos reglamentarios 221/009, 400/2009 y 523/009 refiriendo principalmente a aspectos procedimentales, destacando el vínculo con la evaluación ambiental (Imagen 5).

El Decreto Departamental 10/2016, aprobó el Plan Local de Ordenamiento Territorial y Desarrollo Sostenible de la ciudad de Florida y su Micro Región. Sus objetivos remitían a: regular, orientar y controlar el desarrollo, crecimiento y funcionamiento de la ciudad y su entorno. La delimitación del ámbito de acción del plan recupera el viejo ejido de la ciudad y la zona de chacras de la ciudad-territorio fundacional como "microregión" y refuerza esta histórica carcaza geográfica como área próxima (Imagen 6). La delimitación de ámbitos de actuación de los planes locales ha sido un tema abordado de diferentes maneras por las intendencias departamentales, considerando diferentes criterios en base a subdivisiones administrativas, u otras huellas de conformación territorial en que las viejas zonas de chacras o los ejidos definidos en los trazados fundacionales han tenido un papel relevante en la identificación de las "microrregiones" en torno a los centros urbanos (Robayna, 2018). 


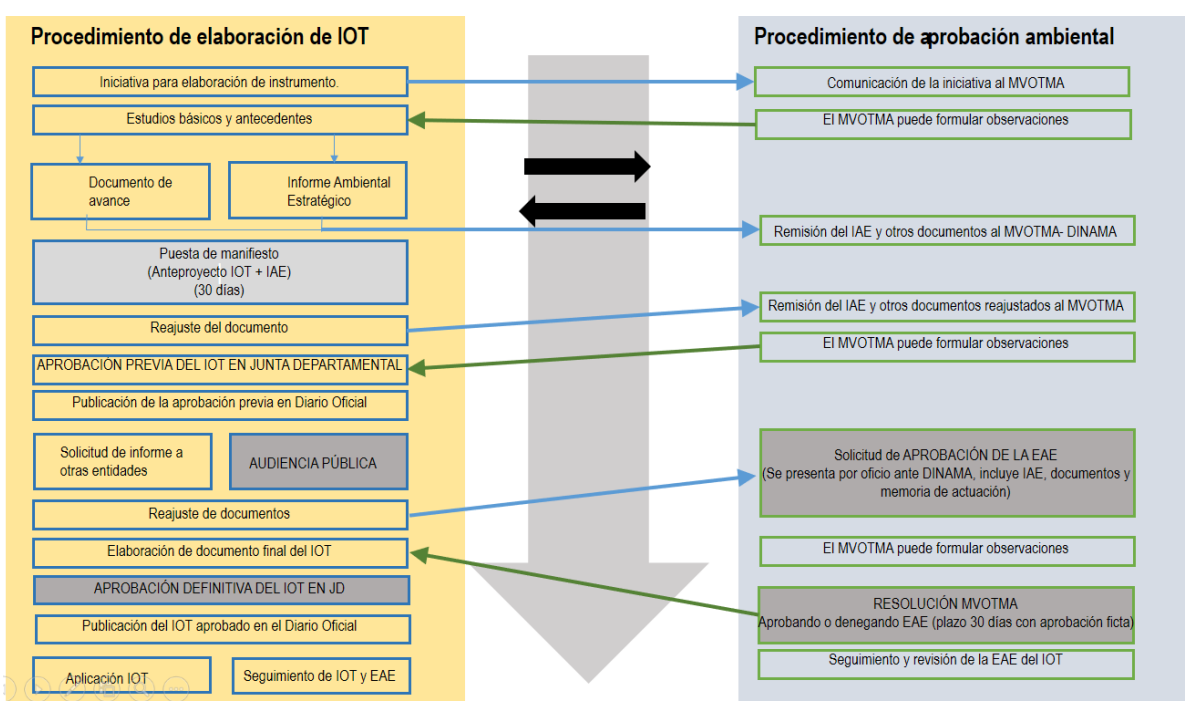

Imagen 5.

Esquema de procedimientos para la elaboración de IOT

Elaboración propia a partir de Cousillas,2010; MVOTMA, 2019; Dec 221/09

Los criterios para la categorización de suelos no están especificados en ninguna disposición que reglamentó la LOTDS, más allá de las definiciones de las categorías mencionadas en los artículos 32 a 34 de la norma. Es decir, los gobiernos departamentales toman sus propios criterios para hacerlo, más allá de los intentos de la Dirección Nacional de Ordenamiento Territorial (DINOT) en la generación de Guías Metodológicas (orientadoras y no vinculantes, dentro del respeto a la autonomía departamental) que, además de criterios de categorización de suelos, sugieren un proceso conceptual y de contenidos dentro de la elaboración de los IOT. En el caso de planes locales refiere a definir una imagen objetivo y un modelo Territorial (en tanto sistema urbano-territorial, movilidad laboral o por acceso a servicios, uso del suelo), sistema de centralidades urbanas, posibles instrumentos de planificación derivada en ámbitos específicos, áreas caracterizadas, y normas de gestión.

En el apartado del Plan Local de Florida y su microregión referente al diagnóstico, uno de los puntos menciona la "descripción del modelo territorial existente y determinación de sus disfuncionalidades" (Ministerio de Vivienda, Ordenamiento Territorial y Medio Ambiente, 2014, p. 30).

Al analizar el Plan Local de Florida (IDF, 2016) en sus documentos constitutivos: exposición de motivos, articulado (que incluye la categorización de suelos) y cartografía, clasificamos los nodos problemáticos conceptuales y espaciales desde el diagnóstico y propuesta.

- El modelo territorial heredado: Refiere a aspectos de la trayectoria de la ocupación del suelo y su situación al momento de la elaboración del Plan. Se incluyen tanto el diagnóstico como las condicionantes de ocupación del suelo urbano, respecto a limitaciones topográficas, hidrográficas o ambientales. Se aprecian dos dimensiones principales: el riesgo hídrico de aguas urbanas y la recurrencia de inundaciones vinculadas al Río Santa Lucía y afluentes. Por otra parte, la actividad industrial de diversa escala en la ciudad y su entorno y sus efectos sobre el medioambiente y la presencia del vertedero municipal de basura. 
- El modelo territorial propuesto: Implica la actuación del Plan en torno a los procesos de transformación del suelo urbano y otras dimensiones con implicancia territorial. Pueden identificarse de la lectura del instrumento dos grandes ejes conceptuales del modelo propuesto: usos del suelo urbano, y disposiciones que no pasan por la categorización de suelos.

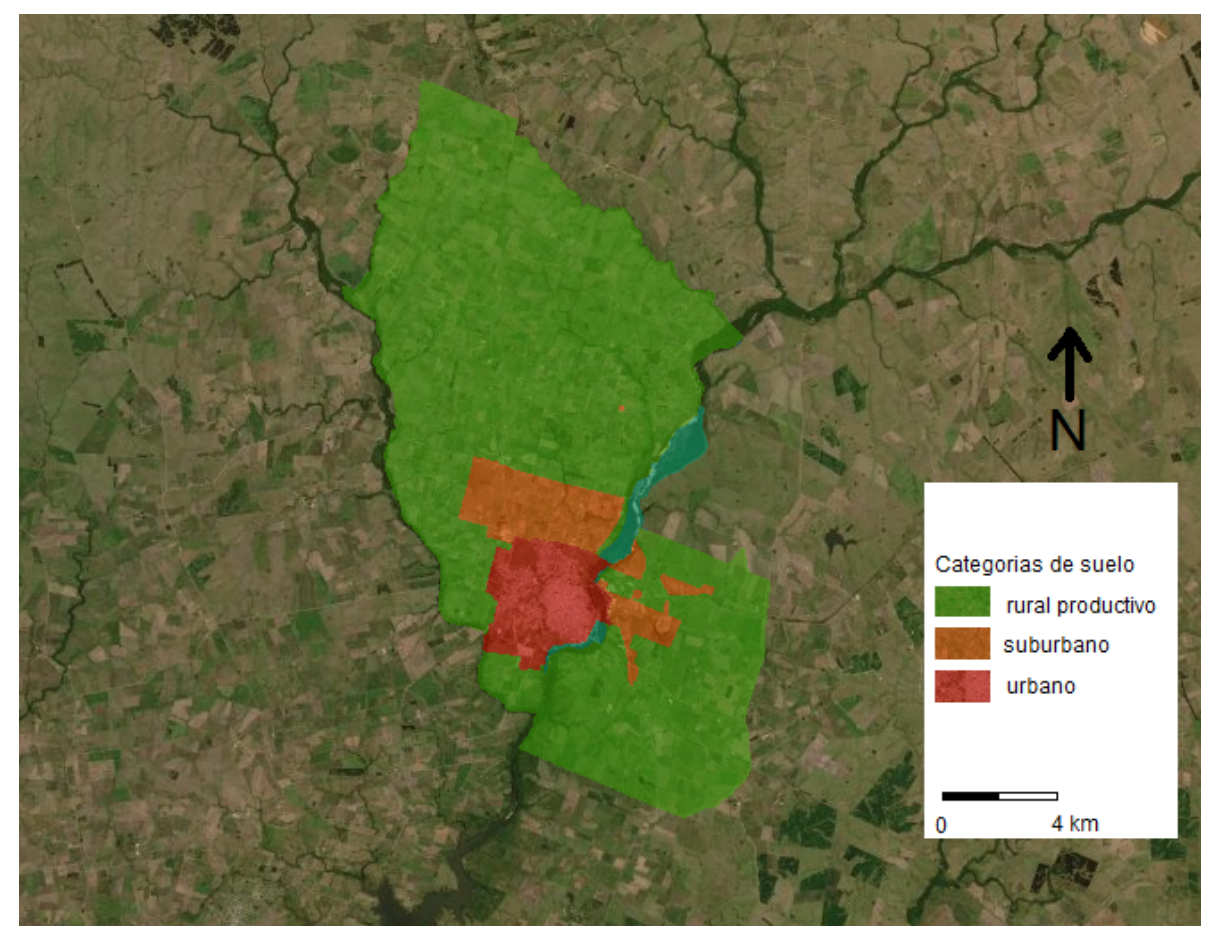

Imagen 6.

Ámbito de acción del Plan Local de Florida.

Inventario nacional de Ordenamiento Territorial

Sobre las orientaciones del Plan que no refieren a las disposiciones de uso del suelo, en ella aparecen orientaciones de tipo estratégico en coordinación con otros entes públicos y actores privados y sociales en una variedad tal que no permite definir categorías claras en función de la LOTDS. A su vez estas orientaciones se dan en un marco de acción que supera las competencias de los gobiernos departamentales.

Respecto a los territorios de borde urbano, dinámicos y heterogéneos que constituyen un claro proceso de periurbanización, el plan ni en su diagnóstico o propuesta, califican estas dinámicas territoriales a partir de ese concepto.

Sin embargo, observando el diagnóstico y propuesta en torno a los sectores urbanos no consolidados (periferia urbana), suelos suburbanos y aquellos rurales con el atributo de potencialmente transformable a urbano o suburbano, evidencian esta configuración, en la cual pueden apreciarse algunas tendencias condicionadas por decisiones ad hoc de radicación de industrias al sur de la ciudad que han devenido en que el crecimiento con usos habitacionales deba direccionarse al oeste y norte, donde la ciudad pierde continuidad en su trazado por la presencia de ruta 5 y la vía del tren, así como de la cercana presencia del vertedero municipal. Por otro lado, al norte, dentro del sector "Chacras de Florida", se aprecia una multiplicidad de usos (Imagen 7). 


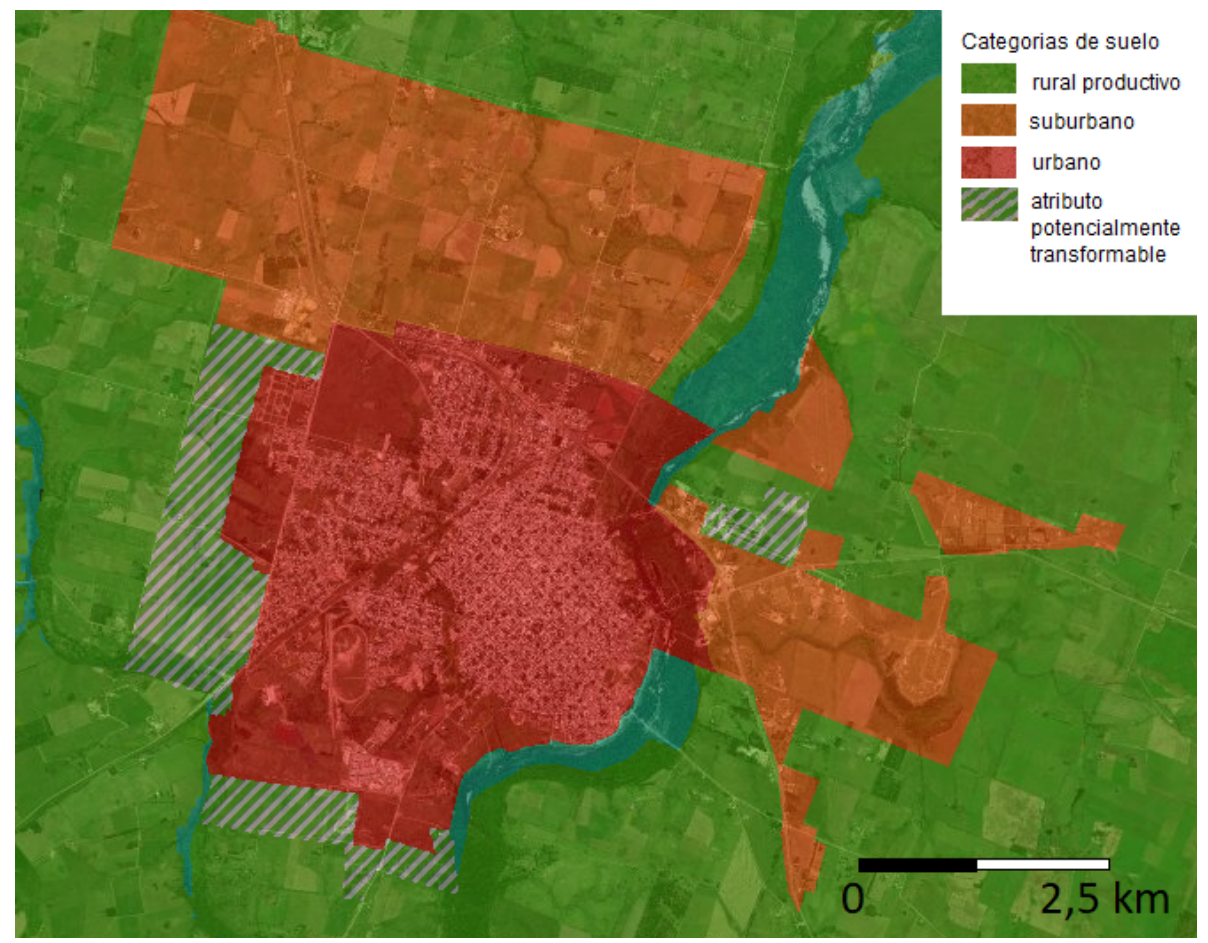

Imagen 7.

Categorización primaria del suelo según el Plan Local de Florida (2016). Inventario Nacional de Ordenamiento Territorial

En la definición de los sectores suburbanos y rurales con atributo de potencialmente transformable, contiguo o próximo al suelo urbano, así como los sectores urbanos no consolidados, el Plan menciona (ver imagen 7):

- Sector "Chacras de Florida" (suburbano): creadas en la época fundacional de Florida, con el propósito de abastecer a la misma fundamentalmente de recursos alimenticios. En la actualidad en esta zona conviven diversas actividades y usos del suelo que la han convertido en una zona con gran cantidad de emprendimientos de distinta índole como ser pequeñas industrias (aserraderos, hornos de ladrillos, etc.) actividades comerciales, recreativas, depósitos, habitacional con residencias permanente y temporal, actividades agropecuarias, etc. ${ }^{5}$

- Zona cortijo y calle $N^{\circ} 60$ (urbano no consolidado): Zona de expansión de la ciudad, en virtud a la existencia de barreras físicas y naturales que obstaculizan el libre crecimiento hacia otras zonas.

- Zona Industrial (urbano no consolidado. Zona especial): Sector que históricamente ha tenido uso industrial de significativo impacto ambiental pero de gran importancia laboral que ha incidido de forma permanente en la población de la ciudad. Se caracterizó como industrial por tener los servicios e infraestructura necesarios para tal fin, con asiento de emprendimientos de gran porte y cuya reubicación es inviable e incompatibiliza fraccionamientos residenciales próximos o contiguos. 


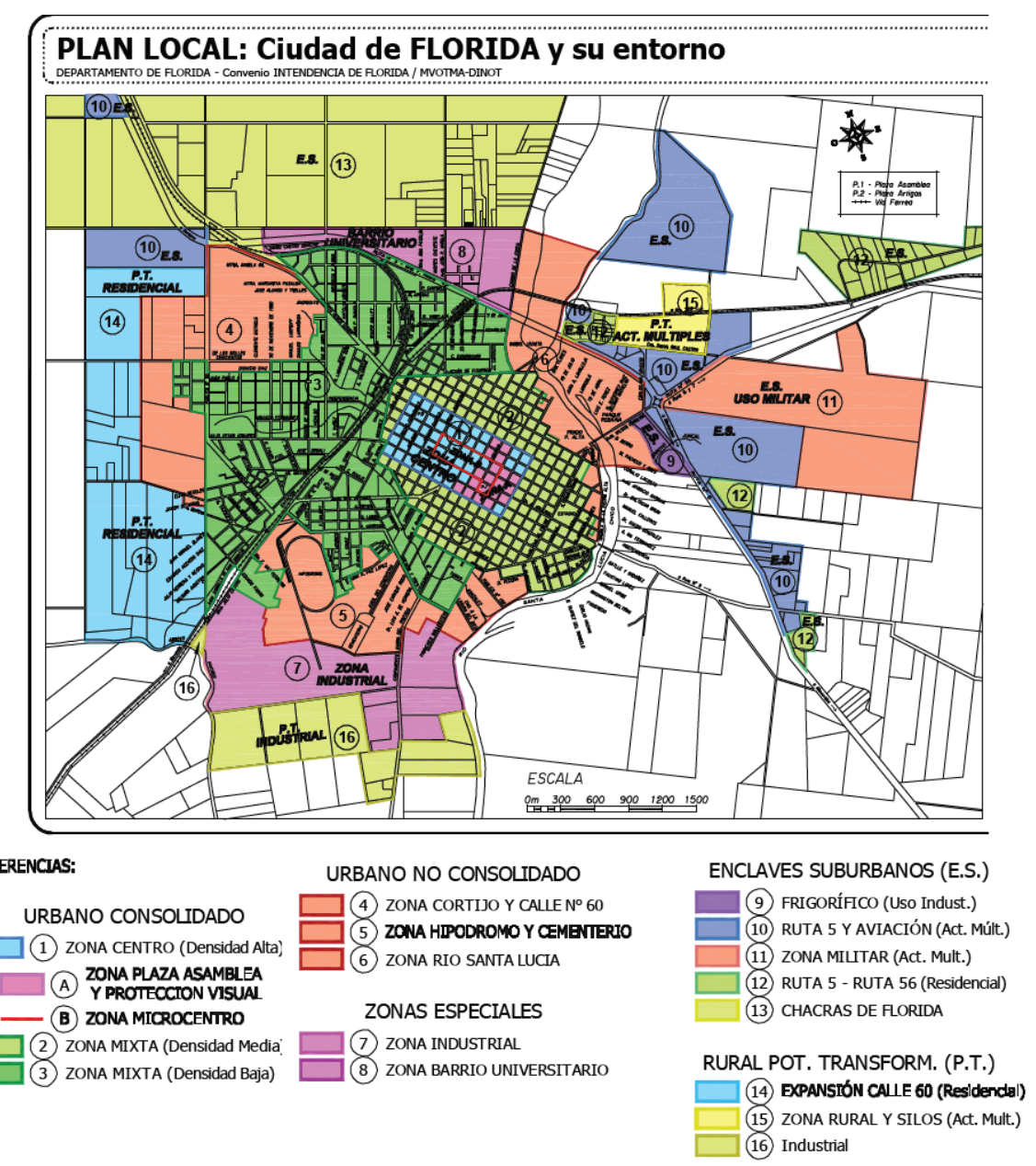

\section{Imagen 8.}

Categorización y zonificación. Plan Local de Florida.

Plan Local de Florida y su microrregión.

- Barrio Universitario (urbano no consolidado): zona de borde, cerca de ruta nacional $\mathrm{N}^{\circ} 5$ y vía férrea, se plantean usos habitacionales, comerciales e industriales de bajo impacto, logísticos.

- Ruta $N^{\circ} 5$ y Aviación (Enclave suburbano. Actividades Múltiples): zona con emprendimientos logísticos y de servicios que surgen por la dinámica por la presencia de la Ruta $N^{\circ} 5$.

- Zona militar (Enclave suburbano. Actividades Múltiples): Sus actividades no suelen resultar acordes con el suelo rural (Divisiones del Ejército Nacional y el Departamento de Fabricaciones y Polvorines del Servicio de Material y Armamento), con sus respectivas instalaciones y viviendas para el uso del personal.

- Ruta $N^{\circ} 5$ y ruta $N^{\circ} 56$ (Enclave suburbano. Destino Residencial): Son variados emprendimientos que fueron surgiendo en el transcurrir del tiempo con características diferentes con destino habitacional en amplios predios de baja densidad que remite a la urbanización campestre. 


\section{Conclusiones: la tensión local entre innovaciones normativas nacionales de uso del suelo y la presión de dinámicas territoriales multiescalares}

El análisis de la gestión territorial del periurbano desde el estudio de los instrumentos de ordenamiento territorial uruguayos se revela como un ámbito de singular interés para apreciar cómo estos dinámicos procesos territoriales dialogan con marcos de uso del suelo que establecen patrones de ocupación rígidos y de mediano y largo plazo, así como el carácter pluriescalar de los procesos de urbanización

La categorización del suelo planteada en el plan local de Florida validó los procesos territoriales acumulados de decisiones ad hoc y de marcos previos. Ligrone (2013) ha planteado a nivel general las dificultades operativas de la implementación local del Ordenamiento Territorial y algunas modificaciones a la normativa nacional que han devenido en rigideces que promueven un modelo excesivamente jerárquico y piramidal desde la planificación departamental hacia los ámbitos locales.

El estudio del Plan Local de Florida, muestra como la implementación de un modelo de territorio, intenta convivir con éstas configuraciones heredadas. En efecto, se utiliza todo el aparato normativo nacional y local del ordenamiento territorial para consolidar como proyecto territorial un crecimiento tendencial en los grandes patrones de uso del suelo del modelo heredado, en particular la generación de una zona industrial al sur de la ciudad, los enclaves agroindustriales de gran porte (frigorífico, planta industrial lechera) y la zona franca. Estas tendencias son claramente observables tanto en designación de categorías y subcategorías de suelo como en la asignación del atributo de potencialmente transformable. Este recurso también fue utilizado para consolidar polos residenciales respecto a las urbanizaciones de tipo campestre o jardín al este de la ciudad, y el crecimiento de la ciudad formal en base a fraccionamientos, hacia el oeste. En este último caso, se ha intentado articular la categorización contigua de zonas urbanas no consolidadas con otras rurales con atributo potencialmente transformable a urbano.

Sobre el dinamismo de reconversión productiva a usos múltiples de zona más próxima a la ciudad de la vieja zona de chacras su designación como "suburbano" en las áreas próximas a la ciudad (el resto permanece como rural productivo) con una normativa que habilita la coexistencia de emprendimientos residenciales, logísticos, industriales y productivos, muestra no sólo el carácter polifacético de ésta categoría en el marco de la LOTDS, sino que valida un proceso de ocupación heterogéneo, pero acotado espacialmente.

Finalmente, dentro de esa ocupación del suelo y actividades, aparece la impronta del reescalamiento del sector primario uruguayo: la logística e instalaciones derivada del polo agroindustrial que la ciudad es (frigoríficos, lechería, forestación, zona franca, lanera) también muestra implicancias de las escala nacional, regional, y global, que nos devuelve la imagen de una ciudad intermedia inserta tramas multiescalares (Guibert et al, 2011; Gorenstein et al, 2012) que resignifican la relación rural-urbano y el propio proceso de urbanización contemporáneo, así como los alcances de herramientas de planificación y gestión locales, estas microgeografías regulatorias. 


\section{Referencias}

ALLEN, A. (2003). La interfase periurbana como escenario de cambio y acción hacia la sustentabilidad del desarrollo. Cuadernos del CENDES 20(53), 7-21

ARTIGAS, A., CHABALGOITY, M., GARCÍA, A., MEDINA, M., TRINCHITELLA, J. (2002). "Transformaciones socio-territoriales del Área Metropolitana de Montevideo". EURE (Santiago) 28(85), 151-170. https://doi .org/10.4067/s0250-71612002008500008

ALTMANN MACCHIO, L. (2018) "Del ejido al periurbano. Dos casos de reconfiguración de periferias en ciudades intermedias uruguayas". Actas del Seminario Internacional de Investigación en Urbanismo. X Seminario Internacional de Investigación en Urbanismo, Barcelona-Córdoba, Junio 2018. Barcelona: DUOT, 2018. http://hdl.handle.net/2117/134737

ALVAREZ LENZI, Ricardo (1972). Fundación de poblados en el Uruguay, Montevideo: Instituto de Historia de la Arquitectura, Facultad de Arquitectura, Universidad de la República.

AMIN, A. (2005). Regiones sin fronteras: hacia una nueva política de lugar, Revista Ekonomiaz, N58, San Sebastián.

ASCHER, F. (1995). Métapolis ou l'avenir des villes. París: Odile Jacob.

AVILA SANCHEZ, H. (2001). Ideas y planteamientos teóricos sobre los territorios periurbanos. Las relaciones campo-ciudad en algunos países de Europa y América. Investigaciones Geográficas, Boletín del Instituto de Geografia. UNAM, 45, 108-127.

BARSKY, Andrés (2005): El periurbano productivo, un espacio en constante transformación. Introducción al estado del debate, con referencias al caso de Buenos Aires. Scripta Nova, vol. IX, núm. 194.

BRENNER, N.; SCHMID, C. (2015). Towards a new epistemology of the urban? City, 19(2-3), 151-182. https://doi.org/10.1080/13604813.2015.1014712

BRENNER, N. (2004). New States Spaces. Londres: Oxford.

CABELLA, W.; SOTO PRIETO, V.; FERNÁNDEZ, M. (2015). Atlas sociodemográfico y de la desigualdad en Uruguay. Fascículo 6. Las transformaciones de los hogares uruguayos vistas a través de los censos de 1996 y 2011 . Montevideo: INE- UNPFA- MIDES.

CARTER, Harold. (1974). El estudio de la Geografía Urbana. Madrid: Instituto de Estudios de Administración Local.

COLLEDGE, R.G (1960) Sydney's metropolitan fringe: a study in urban-rural relations. Australian Geographer, Vol. 7, nº 6, p. 243-255.

GOLDARACENA, P. (2008.). Las nuevas urbanizaciones en el periurbano este metropolitano: la planificación fisica, la gestión y el diseño del territorio. Tesis de maestría en ordenamiento territorial y desarrollo urbano. Universidad de la República (Uruguay). Facultad de Arquitectura Diseño y Urbanismo.

GORENSTEIN, S.; LANDRISCINI, G.; HERNÁNDEZ, J. (comp.). (2012). Economia Urbana y Ciudades Intermedias. Ed. CICCUS. Buenos Aires.

GUIBERT, M.; GROSSO, S.; ARBELECHE, P.; BELLINI, M. (2011). De Argentina a Uruguay: espacios y actores en una nueva lógica de producción agrícola, en Revista Pampa, 7, 13-38.

KLACZKO, J. (1981): El Uruguay de 1908. Su contexto urbano-rural. Antecedentes y perspectivas. Montevideo, Cuadernos del CIESU, 42.

KLACZKO, J.; RIAL, J. (1981). Uruguay: pais urbano. Montevideo: Banda Oriental. 
HERNÁNDEZ PUIG, S. (2012). El periurbano, un espacio estratégico de oportunidad. Biblio 3W. Revista Bibliográfica de Geografia y Ciencias Sociales [en línea]. Barcelona: Universidad de Barcelona, Vol. XXI, nº 1.160.

INDOVINA, F. (2005 [1991]). La ciudad difusa, en Ramos, A.M. (ed) en Lo urbano en 20 autores contemporáneos. Barcelona: Ediciones UPC.

INTENDENCIA DEPARTAMENTAL DE FLORIDA (2016).Plan Local de Florida y su microrregión.

LASCOUMES, P.; LE GALÈS, P. (2014). Sociologia de la acción pública. El Colegio de México.

LIGRONE, P. (2013). Transformaciones, seudoplanificación y territorios inteligentes, Revista de la Facultad de Arquitectura, 10, 64-79.

LIGRONE, P. (2016). Manejo de bordes de crecimiento urbano en Uruguay. Bitácora Urbano Territorial, 26(1), 73-82. https://doi.org/10.15446/bitacora.v26n1.431 82

MARTÍNEZ, E.J.;ALTMANN MACCHIO, L. (2016). "Entre macrocefalia estructural y policentrismo emergente. Modelos de desarrollo territorial en Uruguay (1908-2011)". Montevideo: UCUR CSIC UDELAR.

MARTÍNEZ, E.J.;ALTMANN MACCHIO, L. (2020). Ciudades intermedias del Uruguay. Procesos urbanos y acondicionamiento del suelo (1985-2011). Montevideo: UCUR CSIC UDELAR.

MEDINA, M. (2017). Montevideo y su área metropolitana. Estructuración territorial y contexto planificador, RIURB, 13. Barcelona, 65-88.

Ministerio de Vivienda, Ordenamiento Territorial y Medio Ambiente; Dirección Nacional de Ordenamiento Territorial (2014). Guias para la elaboración de instrumentos de ordenamiento territorial y desarrollo sostenible. Montevideo, Uruguay.

MUSSO, C. (2004). Las ciudades del Uruguay. Montevideo: Facultad de Arquitectura.

ODDONE, G. (2010). El declive: una mirada a la economía de Uruguay del siglo XX. Montevideo: Linardi y Risso.

PARK, R.; BURGESS, E.; MCKENZIE, R. (1925). The City. Chicago: The University of Chicago Press.

PRADILLA COBOS, E. (2014) "La ciudad capitalista en el patrón neoliberal de acumulación en América Latina", en Caderno Metropole, São Paulo, 16(31), 37-

ROBAYNA SOSA, A. (2018). Delimitación territorial en el marco de la Ley $N^{o}$ 18.308: Análisis de los planes locales aprobados entre 2008-2015 con énfasis en el departamento de Paysandú. Tesis de maestría. Universidad de la República (Uruguay). Facultad de Arquitectura Diseño y Urbanismo.

SCHELOTTO, S.; LECUNA, C. (2015). Alteraciones dinámicas en espacios periurbanos: el caso de la Ruta 101. VII Seminario Internacional de Investigación en Urbanismo, Barcelona-Montevideo. Text en actes de congrés presented at the VII Seminario Internacional de Investigación en Urbanismo, Barcelona: Departament d'Urbanisme i Ordenació del Territori. Universitat Politècnica de Catalunya.

THOENIG, J.C. (1997). “Política pública y acción pública”. Revista Gestión y Politica pública, VI, 1, México, 19-37. 


\section{Fuentes}

REPÚBLICA ORIENTAL DEL URUGUAY. Leyes 10723 (de centros poblados), 18308 (de ordenamiento territorial y desarrollo sostenible).

Inventario Nacional de Ordenamiento Territorial- Uruguay. Dirección Nacional de Ordenamiento Territorial. https://sit.mvotma.gub.uy/inot/

Mapoteca digital de la Biblioteca Nacional de Uruguay: http://bibliotecadigital.bibna. gub.uy:8080/jspui/handle/123456789/8

\section{Notas}

1 Para el caso uruguayo ver Klaczco (1981).

2 Este apartado toma elementos desarrollados en ALTMANN MACCHIO, L. (2018) "Del ejido al periurbano. Dos casos de reconfiguración de periferias en ciudades intermedias uruguayas". Actas del Seminario Internacional de Investigación en Urbanismo. "X Seminario Internacional de Investigación en Urbanismo, BarcelonaCórdoba, Junio 2018". Barcelona: DUOT, 2018. http://hdl.handle.net/2117/13473 7

3 Las Zonas Francas, regidas en Uruguay por la ley 15921 (del año 1988) son ámbitos de propiedad pública o privada autorizadas por el Poder Ejecutivo Nacional para llevar adelante actividades industriales, comerciales o de servicios dentro de un régimen legal de exoneraciones tributarias y aduaneras. Además, al ser ámbitos donde no rigen los monopolios del estado y donde existe libertad total para el ingreso y salida de bienes, activos de capital fijos con exenciones en impuestos, funcionan como ámbitos desterritorializados de la geografía regulatoria nacional. En el caso de Florida, fue la primera zona franca privada habilitada fuera del departamento de Montevideo (1993). Según Uruguay XXI (Dependencia del Ministerio de Relaciones Exteriores uruguayo), en la Zona Franca de Florida están instaladas 200 empresas.

4 Las competencias de los gobiernos departamentales están establecidas en las leyes 9.515 (Ley Orgánica Departamental, de 1935) y 19.272 (De descentralización política y participación ciudadana, de 2014).

5 En el sector suburbano de "Chacras de Florida", los predios serán de mínimo $1500 \mathrm{~m} 2$ y $50 \mathrm{mts}$ de frente, se autorizan los usos: Vivienda Individual (una por padrón), actividades Comerciales, Logísticas y de Servicios, Actividades rurales que compatibilicen con la residencia. Y solo en los predios más alejados al noroeste, se admitirán: salones de Fiesta y/o similares, Actividades Industriales de bajo impacto ambiental, locales Bailables y/o similares, Prostíbulos y/o similares. Quedan prohibidos los Fraccionamientos y Urbanizaciones en Propiedad Horizontal, las Cooperativas de vivienda y las actividades de mediano y alto Impacto ambiental.

\section{Notas de autor}

Sobre el autor

Arquitecto (UDELAR, Uruguay). Magister y Doctorando en Estudios Urbanos (UNGS, República Argentina). Docente e investigador en urbanismo y ordenamiento territorial. Se desempeña en el Instituto de Estudios Territoriales y Urbanos. Facultad de Arquitectura, Diseño y Urbanismo. Universidad de la República Oriental del Uruguay (IETU- FADU- UDELAR), el departamento de Planificación y Evaluación de la Dirección Nacional de Integración Social y Urbana (Ministerio de Vivienda y Ordenamiento Territorial de Uruguay) y el think tank "Centro de Estudios para el Desarrollo". 